\title{
The Roles of Challenge and Skill in the Flow Experiences of Web Users
}

\author{
Steven Pace \\ Central Queensland University, Mackay, Australia
}

s.pace@cqu.edu.au

\begin{abstract}
Numerous researchers have employed Csikszentmihalyi's flow theory in their analyses of the behavior of Web users. Flow is a state of consciousness that is experienced by people who are deeply involved in an enjoyable activity such as surfing the Net. The experience is characterized by some common elements such as concentration on the task at hand, a sense of control, a merging of action and awareness, a distorted sense of time, and the autotelic experience, to mention a few. A recognized precondition for flow is that the challenges an individual faces in a particular activity must be matched by the skills he or she uses in meeting those challenges. This paper discusses the roles that challenge and skill play in the flow experiences of Web users.
\end{abstract}

Keywords: enjoyment, flow, grounded theory, World Wide Web

\section{Introduction}

Numerous researchers in the field of information systems have employed Csikszentmihalyi's $(1975,1990)$ flow theory in their analyses of the behavior of Web users, particularly within the context of online shopping (Agarwal \& Karahanna, 2000; Chen, Wigand \& Nilan, 1998, 1999, 2000; Hoffman \& Novak, 1996; Koufaris, 2002; Nel, van Niekerk, Berthon \& Davies, 1999; Novak, Hoffman \& Yung, 2000). Flow is a state of consciousness that is sometimes experienced when one's attention is intently focused on an enjoyable activity. Flow experiences can be distinguished from the rest of everyday life by a common set of structural characteristics: a balance between the challenges of an activity and the skills required to meet those challenges; clear goals and feedback; concentration on the task at hand; a sense of control; a merging of action and awareness; a loss of self-consciousness; a distorted sense of time; and the autotelic experience (Csikszentmihalyi, 1975, pp. 35-54; 1990, pp. 48-70). The term autotelic refers to an activity that is 'worth doing for its own sake even though it may have no consequence outside itself' (Csikszentmihalyi, 1999, p. 824). To illustrate these ideas, consider the following description of a flow experience provided by a 35-year-old male Web user:

... I just come home from work and I just want to relax and I'll sit in front of the computer. You know, I'm tired and I'll think, 'I'll just surf the Web for a half hour or something and go to bed'. And before you know it, it's like two or three hours have gone... Sometimes my wife will be going to bed and she may put a load of washing on and she'll say, 'Can you just hang that out when it finishes'. 'Yeah righto'. And then you totally forget all about it

Material published as part of this journal, either on-line or in print, is copyrighted by Informing Science. Permission to make digital or paper copy of part or all of these works for personal or classroom use is granted without fee provided that the copies are not made or distributed for profit or commercial advantage AND that copies 1) bear this notice in full and 2) give the full citation on the first page. It is permissible to abstract these works so long as credit is given. To copy in all other cases or to republish or to post on a server or to redistribute to lists requires specific permission from the publisher at Publisher@InformingScience.org
... You know she spoke to you, but you just push it to the back of your mind and carry on ... When you're really concentrating on one thing, you just don't retain any information about another thing.

A recognized precondition for flow is that the challenges an individual faces in a particular activity must be matched by the skills he or she uses in 
meeting those challenges (Csikszentmihalyi 1975, pp. 49-54; 1990, pp. 49-53). Flow theory suggests that if the challenges of an activity are too high relative to one's skills, one experiences anxiety. If challenges are too low, one experiences boredom. If challenges and skills are both low, one experiences apathy and the overall quality of the subjective experience is the lowest. If challenges and skills are both high, the likelihood of experiencing flow is maximized and the overall quality of the subjective experience is the highest (see Figure 1). This paper discusses the roles that challenge and skill play in the flow experiences of Web users.

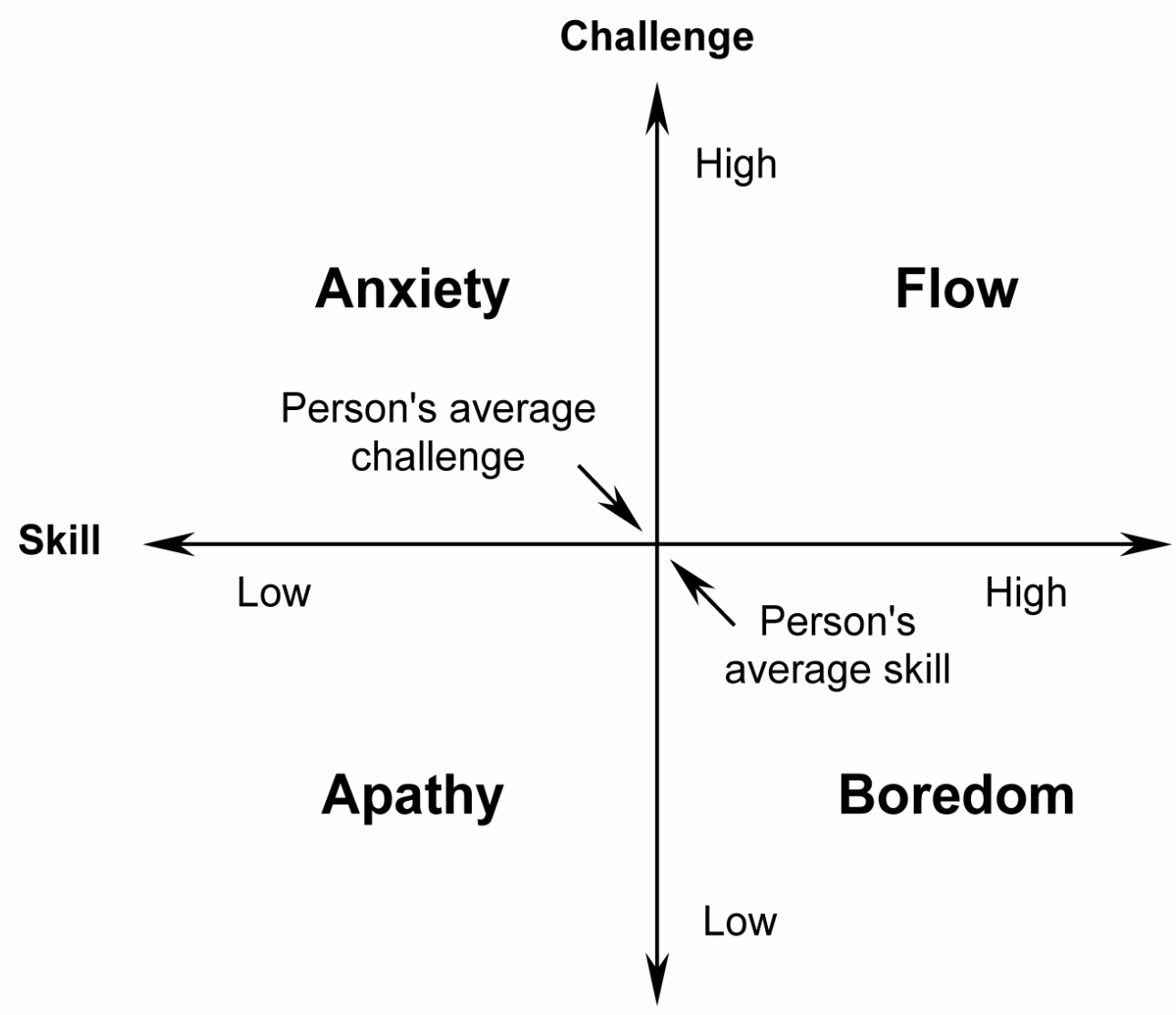

Figure 1: The four-channel flow model. Adapted from Jackson and Csikszentmihalyi (1999, p. 37)

\section{Modeling the Flow Experience}

The first researchers to apply the concept of flow to the experiences of Web users were Hoffman and Novak (1996). Based on their understanding of the literature, they developed a conceptual model that identified specific antecedents that are necessary for experiencing flow, and specific consequences that occur as a result of experiencing flow. Hoffman and Novak's (1996) conceptual model served as the foundation for a structural equation model that was later developed by Novak et al. (2000). Model constructs were operationalized and measured by means of a survey of more than $1600 \mathrm{Web}$ users. Hypothesized relationships between constructs were depicted as path diagrams and translated into a series of structural equations. The resulting model's 'fit' to the data was assessed, and significant paths between model constructs were interpreted as supporting the hypotheses. 
Novak et al. (2000, p. 24) claimed that their study was 'the most comprehensive effort to date to bring quantitative modeling to bear upon the measurement of consumer experience in computermediated environments'. However, their study was criticized by Chen et al. (1999) for failing to operationalize key concepts such as flow, challenge and skill in terms of specific Web activities. Commenting on a working paper produced in 1998, Chen et al. (1999, p. 592) wrote:

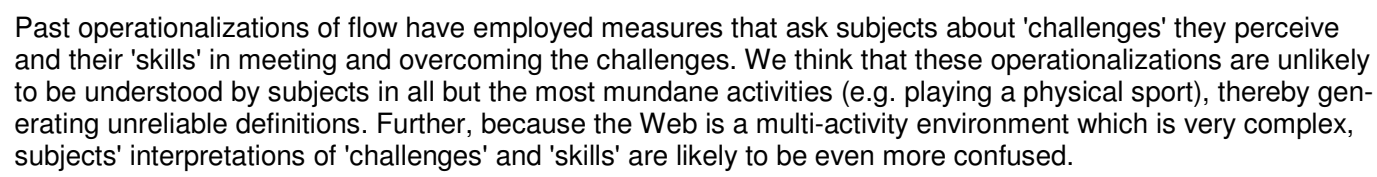

Chen et al's concerns are better understood when one considers the survey items that Novak et al. (2000, p. 28) used to measure the challenge construct. Their survey instrument asked participants to respond to each of the following statements on nine-point rating scales:

- $\mathrm{C} 1$ : Using the Web challenges me.

- $\mathrm{C} 2$ : Using the Web challenges me to perform to the best of my ability.

- C3: Using the Web provides a good test of my skills.

- C4: I find that using the Web stretches my capabilities to my limits.

- C5: How much does the Web challenge you, compared to other things you do on the computer?

- C6: How much does the Web challenge you, compared to the sport or game you are best at?

As Chen et al. (1999) correctly pointed out, these questions operationalize challenge, not in terms of a specific Web activity, but rather as a general experience of Web users. This is problematic because the Web is a rich interactive environment that facilitates many different kinds of activities such as searching and browsing for information, reading and sending e-mail, playing games, chatting with other users, and so on. Since different activities present different challenges and call for different skills, Chen et al. (1999, p. 590) argued that the Web should be viewed as a 'multiactivity medium', and that concepts such as flow, challenge and skill should be operationalized in terms of specific Web activities.

\section{Research Method}

In view of the difficulties that researchers have encountered in their attempts to operationalize various dimensions of the flow experience, a qualitative study was undertaken with the aim of answering the question: What is the nature of flow, as experienced by Web users engaged in information-seeking activities? The study focused on information-seeking because, as Chen et al. (2000) have demonstrated, it is the most dominant flow-inducing activity in the Web environment. One of the secondary aims of this study was to identify the specific challenges that Web users perceive when seeking information.

The research method that was selected for this study was grounded theory-a primarily inductive investigative process that is rarely used within the field of information systems (Glaser, 1978, 1992, 1998; Glaser \& Strauss, 1967). The purpose of the grounded theory method is building theory, not testing theory. Rather than begin a study with a preconceived theory that needs to be proven, the researcher begins with a general area of study and allows the theory to emerge from the data. The results of a grounded theory study are hypotheses or propositions, not findings. Grounded concepts are suggested, not proven. 


\section{Data Collection}

The data that was gathered for this study primarily consisted of semi-structured in-depth interviews with twenty-two informants who could recall experiencing flow while using the Web. Unlike structured interviews, in-depth interviews have a flexible and dynamic style of questioning directed toward understanding the significance of experiences from the informant's perspective. The general interview strategy involves asking open-ended questions about key topics, allowing informants to discuss what is important from their perspective, and probing for details and specific descriptions of their experiences. All of the interviews in this study were tape-recorded with the informants' permission, and later transcribed to provide accurate records for analysis.

The theoretical sampling method used in grounded theory studies is very different to statistical or random sampling, commonly used in quantitative studies. Theoretical sampling involves consciously selecting additional informants according to their potential for providing new insights or refining insights that have already been gained. A theoretical sample does not aim to be representative of a population in the statistical sense. Rather, it aims to maximize opportunities for exploring emerging concepts and relationships.

The gender, age, educational attainments, occupations and Web experience of the informants who participated in this study were consciously varied with the aim of uncovering a broad range of perspectives. The gender balance among the informants was evenly split. There were eleven males and eleven females. The informants' ages ranged from 17 to 55 years, with a mean of 29.5 and a standard deviation of 11.1. The informants' educational attainments ranged from senior secondary school to postgraduate degree level with both secondary and tertiary qualifications well represented.

The informants' occupations were also quite varied. They included four undergraduate students, two postgraduate students, two administrative assistants, two computer technicians, two kitchenhands, two librarians, two software developers, one apprentice electrician, one junior clerk, one public relations officer, one teacher's aide, one Web designer, and one university lecturer. The informants' diverse levels of experience with the Web will be discussed later in this paper.

\section{Data Analysis}

As with much qualitative research, data collection and data analysis occurred simultaneously in this study. The first stage of analysis, called open coding, involved breaking the interview transcripts down into discrete incidents—objects, events, actions, ideas, and so on—which were closely examined and compared for significant concepts. These concepts were abstractions in the sense that they represented elements of not one informant's story, but rather the stories of many informants. Qualitative analysis software named NVivo (formerly NUD*IST) was used to label incidents in the data with codes that identified pertinent concepts, and to write theoretical memos that captured the researcher's momentary thoughts.

The second stage of analysis, called theoretical coding, involved taking the concepts that emerged during open coding and reassembling them with propositions about the relationships between those concepts. The relationships, like the concepts, emerged from the data through a process of constant comparison. Neither the concepts nor the relationships were preconceived or forced upon the data.

The third stage of analysis, called selective coding, involved delimiting coding to only those concepts and relationships that related to the core explanatory concept reflecting the main theme of the study - flow. Selective coding helped to produce a more focused theory with a smaller set of high-level concepts. 


\section{The Grounded Theory}

The grounded theory that emerged from this study is presented as a concept map in Figure 2. The boxes in the diagram represent concepts and the arrows represent relationships between concepts. Each box in the diagram is numbered so that concepts may be easily referred to in this paper. The number in square brackets that appears inside each box and alongside each arrow represents the number of informants whose comments provided empirical indicators for that particular concept or relationship.

Pace (2004) provides a relatively comprehensive explanation of the overall theory and the concept map shown in Figure 2. This paper is primarily concerned with the elements of the theory that relate to challenge and skill. Elements of the theory that are outside the focus of this paper will be briefly described where appropriate to help contextualize the discussion.

\section{Challenges}

The study's informants reported engaging in two general types of navigation behavior: a directed searching mode in which one is motivated to find a particular piece of information, and an exploratory browsing mode that is more experiential in nature and characterized by diffuse motives such as passing time or seeking stimulation.

It was apparent from the informants' comments that regardless of whether a Web user is engaged in directed searching or exploratory browsing, the individual has a goal of finding some item of interest quickly (see box 3 in Figure 2). Web users engaged in directed searching have a clearly defined goal, and those engaged in exploratory browsing have an ill-defined goal, but the important point is the presence of a goal in each case. Goals are a characteristic feature of flow experiences (Csikszentmihalyi, 1990, pp. 54-58). The information-seeking goals of Web users stem from two factors: curiosity or interest in a particular topic, and a sense of time urgency (see boxes 1 and 2 in Figure 2).

Web users face certain mental challenges as they pursue their information-seeking goals (see box 6 in Figure 2). Applying open coding to the informants' comments revealed the following array of challenges, each of which will be discussed in the sections that follow:

- negotiating a vast, constantly changing, uncharted information space;

- selecting suitable key words for a search engine query;

- using the correct syntax for a search engine query;

- distinguishing relevant links from irrelevant links;

- dealing with a large collection of potentially relevant links;

- scanning a page for relevant information; and

- understanding the content and non-linear structure of a Web site. 


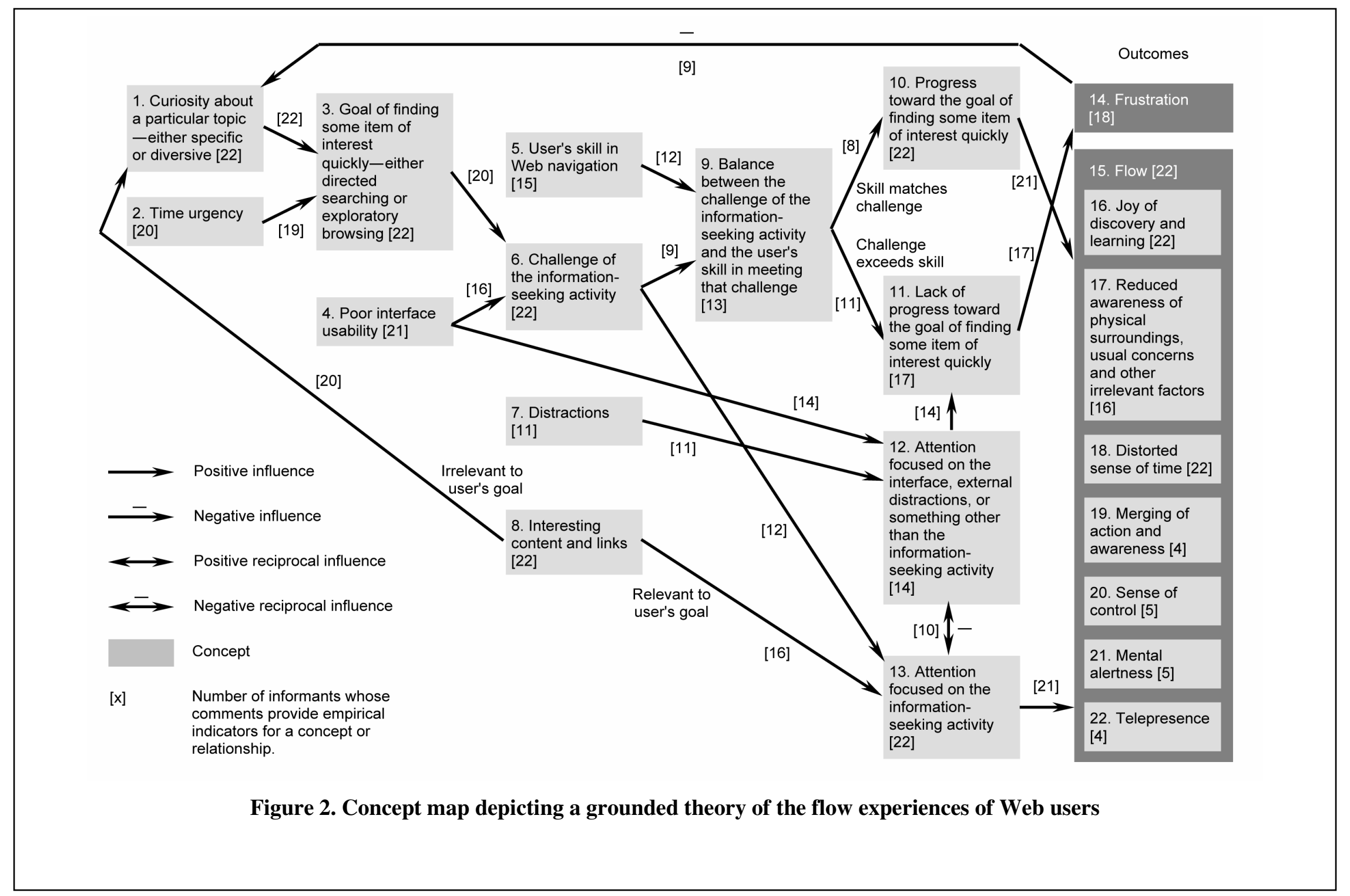




\section{Negotiating a Vast, Changing, Uncharted Information Space}

One of the challenges facing Web users as they search or browse for information is negotiating the vast, constantly changing, uncharted information space that is the Web. The sheer amount of information that is available online makes finding anything a challenge. Not only is the information on the Web voluminous, it is constantly changing and is not indexed in any conventional manner. As Informant 1 noted, 'There's so much out there that you'll go there one day and then you'll come back, and you'll actually end up on a different path and finding something different'. Table 1 provides some other comments from informants describing the challenge of negotiating a vast, constantly changing, uncharted information space.

Table 1. Sample comments from informants describing the challenge of negotiating a vast, changing, uncharted information space.

\begin{tabular}{|l|l|}
\hline Informant & Comment \\
\hline 5 & $\begin{array}{l}\text { Unless you have a specific URL it's hard ... It creates more problems unless you have a } \\
\text { specific address. It's just so ... huge and you have no idea which end to start from. }\end{array}$ \\
\hline 8 & $\begin{array}{l}\text {.. sometimes you can be looking for something specific and with the vast amount of } \\
\text { information on there, sometimes it's quite hard to just find exactly what you're looking } \\
\text { for. It's a case of perseverance. }\end{array}$ \\
\hline 9 & $\begin{array}{l}\text { So I guess I find that more of a challenge, to find exactly what you're looking for be- } \\
\text { cause there is so much information. }\end{array}$ \\
\hline
\end{tabular}

\section{Selecting Suitable Key Words for a Search Engine Query}

Search engines are popular tools for locating Web pages, but the results they return are usually of mixed relevance to the user's query. The key words that make up a query have a direct influence on the relevance of the results that are returned. Key words need to be specific enough to avoid generating a plethora of irrelevant results, but general enough to generate at least some results. Striking the right balance can be difficult. Table 2 provides some comments from informants describing the challenge of selecting suitable key words.

Table 2. Sample comments from informants describing the challenge of selecting suitable key words for a search engine query.

\begin{tabular}{|l|l|}
\hline Informant & Comment \\
\hline 1 & $\begin{array}{l}\text { Actually searching is always challenging 'cause you don't know exactly how to word } \\
\text { what you're looking for. You've actually got to experiment a couple of times to actually } \\
\text { come up with the wording that produces the results that you want. }\end{array}$ \\
\hline 3 & $\begin{array}{l}\text { But probably the most challenging part of it is actually ... when you're in a search engine } \\
\text { and it's looking for that series of words that ... get you where you want to be. So, you } \\
\text { spend a little bit of time trying to get the words right so that you don't have to trawl } \\
\text { through a lot of rubbish. }\end{array}$ \\
\hline 13 & $\begin{array}{l}\text { When I first started in '98 I had a lot of trouble with it. I couldn't communicate what I } \\
\text { wanted to search engines. I think I was using Alta Vista back then. But after a few years } \\
\text { of getting used to what key terms to use, I find I can communicate better. I can speak } \\
\text { 'search engine'. I put the right terms in now, and get rid of the confusing stuff. }\end{array}$ \\
\hline
\end{tabular}




\section{Using the Correct Syntax for a Search Engine Query}

Most search engines allow users to conduct basic searches for information simply by entering a few descriptive key words, but advanced searches usually require the use of operators that have special meaning to the search engine. For example, Google (http://www.google.com) can be instructed to search for a complete phrase rather than individual words by enclosing the phrase in quotation marks. Google also supports the logical OR operator for retrieving pages that include either word A or word B. Table 3 provides some comments from informants describing the challenge of using the correct syntax for a search engine query.

Table 3. Sample comments from informants describing the challenge of using the correct syntax for a search engine query.

\begin{tabular}{|l|l|}
\hline Informant & Comment \\
\hline 3 & $\begin{array}{l}\text {.. very strange ... 'cause this time when I was doing it I'm not sure whether I was actu- } \\
\text { ally putting the quote marks in them to keep it together. I know a couple of times ... } \\
\text { you'll get beef sites. But they're not beef as in we think of beef. They're like sexual beef } \\
\text { sites. You'll have these beefcakes and stuff like this. }\end{array}$ \\
\hline 6 & $\begin{array}{l}\text { Sometimes I'm not sure exactly what key words to type in. Like with Alta Vista if you } \\
\text { type plus (+) whatever plus (+) whatever, it makes sure that it includes both of those } \\
\text { words. But sometimes with different search engines, if you just type in a few words or } \\
\text { whatever it returns results differently to other search engines like Alta Vista might. }\end{array}$ \\
\hline 18 & $\begin{array}{l}\text { I either put ... what I'm looking for in those little inverted commas. I use that a lot. So } \\
\text { that finds the exact phrase of what I'm actually looking for. Or if it's a general topic and I } \\
\text { don't have a phrase, I just put keywords in and use Boolean operators like AND and OR. } \\
\text { And if that doesn't work, if I still can't find exact information, then I'll just e-mail some } \\
\text { friends and see if they know of sites. Usually I've found it by just doing the first two. }\end{array}$ \\
\hline
\end{tabular}

\section{Distinguishing Between Relevant Links and Irrelevant Links}

Distinguishing between relevant and irrelevant links is another challenge that Web users face as they search or browse for information. Very often this challenge arises when inspecting the results generated by a search engine. Search engine results are usually presented as a list of links to Web pages that contain the words in the user's search query. Each entry in the list may consist of a page title or URL followed by a text excerpt showing the context in which the search terms appear on that page. The page title and the text excerpt help users to decide whether the destination page is relevant to their goal or not.

The challenge of distinguishing between relevant and irrelevant links may also arise while inspecting other kinds of links, such as those within the body of a Web page or those on a navigation bar. Links within the body of a Web page can be likened to search engine results in the sense that the surrounding information provides some context, which helps the user to assess the link's relevance. In contrast, the relevance of a link on a navigation bar must often be determined solely on the basis of the link's brief label.

Regardless of whether a link appears within the context of surrounding information or not, determining its relevance to one's goal calls for judgment and discernment on the part of the user. Following an irrelevant link wastes time - something that Web users are keen to avoid. Table 4 provides some comments from informants describing the challenge of distinguishing between relevant links and irrelevant links. 
Table 4. Sample comments from informants describing the challenge of distinguishing between relevant links and irrelevant links.

\begin{tabular}{|l|l|}
\hline Informant & Comment \\
\hline 7 & $\begin{array}{l}\ldots \text { there's so much information on the Web there's a good chance that there's stacks of } \\
\text { information that's crap. And filtering through the crap to find anything that seems useful } \\
\ldots\end{array}$ \\
\hline 14 & $\begin{array}{l}\text { I guess because I am pretty impatient, the challenge is sorting out the wheat from the } \\
\text { chaff ... I guess it's the non-discriminatory nature of it. You get stuff and you then have } \\
\text { to sort through it. And that's the challenge that I find ... The fact that you get a lot of } \\
\text { stuff, and you then have to sift through it. }\end{array}$ \\
\hline 21 & $\begin{array}{l}\text {.. when you search with Google it just comes up with a list for you ... It was difficult in } \\
\text { making choices of which one do I want to pick. }\end{array}$ \\
\hline
\end{tabular}

\section{Dealing With a Large Collection of Potentially Relevant Links}

Search engines often generate thousands of results in response to a single query. Dealing with such a large collection of potentially relevant links can be quite challenging - even overwhelming - for users, as the comments in Table 5 testify. Even pages that present a lengthy index or table of contents can be intimidating.

Table 5. Sample comments from informants describing the challenge of dealing with a large collection of potentially relevant links.

\begin{tabular}{|l|l|}
\hline Informant & Comment \\
\hline 6 & $\begin{array}{l}\text { It was challenging — because there were so many links everywhere — to try and figure out } \\
\text { where to go next and stuff like that. }\end{array}$ \\
\hline 10 & $\begin{array}{l}\ldots \text { if you're trying to find a law act and there's just like fifty million different amend- } \\
\text { ments on different Web sites and that sort of thing. So if you're trying to actually get to } \\
\text { one particular one, it's a bit hard. }\end{array}$ \\
\hline 18 & $\begin{array}{l}\text { Actually locating the specific information that I'm looking for. Because often I just get so } \\
\text { many hits, and I just think, 'How am I going to narrow this down?' So it pretty much } \\
\text { comes down to trying to actually narrow it down to find specifics of exactly what I'm } \\
\text { searching for. }\end{array}$ \\
\hline
\end{tabular}

\section{Scanning a Page for Relevant Information}

Whenever Web users retrieve a new page, they generally scan it for relevant information rather than read it word-for-word, possibly because of their sense of time urgency. Usability studies conducted by Nielsen (2000, p. 104) confirm this observation:

Because it is so painful to read text on computer screens and because the online experience seems to foster some amount of impatience, users tend not to read streams of text fully. Instead, users scan text and pick out keywords, sentences, and paragraphs of interest while skipping over those parts of the text they care less about.

Informant 18 said that during this scanning activity she assesses a site to decide whether she will stay and explore it or move on: 'Once I find out it is a genuine site - they know what they're talking about - I'll start to explore it a bit'. Table 6 provides some other comments from informants describing the challenge of scanning a page for relevant information. 
Table 6. Sample comments from informants describing the challenge of scanning a page for relevant information.

\begin{tabular}{|l|l|}
\hline Informant & Comment \\
\hline 3 & $\begin{array}{l}\text {.. you're only half sort of watching what's happening. You're probably only focusing on } \\
\text { one thing and that's seeing these magic words come up: 'exhibiting beef cattle'. And } \\
\text { that's all you're looking for every time you go to a new page. And if it's not there, you're } \\
\text { back to the next one. See what that looks like. }\end{array}$ \\
\hline 7 & $\begin{array}{l}\text { So I was madly clicking on any information I could find, and in most cases I wasn't read- } \\
\text { ing it. But I was looking at it, making sure that there was information, looking at the title, } \\
\text { looking to see if it was relevant, and printing it out. }\end{array}$ \\
\hline 11 & $\begin{array}{l}\text { Links. The next link. This is what I'm looking for. Have I missed it or not? If not, I keep } \\
\text { on clicking, clicking, backtracking, going forward. And so you look at a page, you don't } \\
\text { read everything there, but you pinpoint what you need and focus on the right informa- } \\
\text { tion. }\end{array}$ \\
\hline
\end{tabular}

\section{Understanding the Content and Non-Linear Structure of a Web Site}

When Web users eventually find a site containing information that they want to read in detail, they face a new challenge - understanding the material. Since Web content is rarely organized in a linear fashion, part of the user's challenge is discerning the logical structure of the site and determining a suitable path through its pages. Informant 8 mentioned that making the wrong choices 'can be a bit overwhelming' because 'you're not sure what you're reading'. Table 7 provides some other comments from informants describing the challenge of understanding the content and nonlinear structure of a Web site.

Table 7. Sample comments from informants describing the challenge of understanding the content and non-linear structure of a Web site.

\begin{tabular}{|l|l|}
\hline Informant & Comment \\
\hline 1 & $\begin{array}{l}\text { Understanding the content, when it gets to the event. Well, because it is challenging con- } \\
\text { tent. }\end{array}$ \\
\hline 9 & $\begin{array}{l}\ldots \text { I guess I was just looking at all sorts of different things in there like, 'What does this } \\
\text { mean and what does this mean?' Kind of linking it all together to form a bit of a picture. }\end{array}$ \\
\hline 22 & $\begin{array}{l}\text { Finding exactly what you want out of a huge site. Being able to find ... categories, and } \\
\text { know how to break down the subject ... Knowing how to get your way around it ... With } \\
\text { most of your sites, you've got your basic links which help you to put it into categories, so } \\
\text { you can easily find the way you're going. But there are ... a lot of sites that I've found } \\
\text { that are pretty broad. And you don't quite know where to go. }\end{array}$ \\
\hline
\end{tabular}

\section{Operationalizing Challenge}

The content of this section goes some way toward implementing Chen et al's (1999) suggestion that the challenges Web users face should be defined in terms of specific activities, rather than as a general experience of Web users. Future studies of the flow experiences of Web users engaged in information-seeking activities could use this information to better operationalize the construct of challenge, and thereby avoid the confusion over the term that has been evident in past studies. 


\section{Skill}

The preceding section identified specific challenges that Web users face during informationseeking activities. Let us now consider the level of navigation skill that is required to experience flow. As mentioned earlier in this paper, past studies show that the likelihood of experiencing flow is maximized when the challenges and skills associated with an activity are both high. On that basis, one might speculate that only expert Web users experience flow. However, the results of this study proved otherwise.

The informants who participated in this study varied considerably in terms of their skill using the Web (see box 5 in Figure 2). Table 8 summarizes the values that the informants provided for four indicators of a Web user's skill level: confidence using the Web, frequency of Web use, hours of Web use per week, and years using the Web.

Table 8. Indicators of the informants' skill using the Web.

\begin{tabular}{|l|l|l|}
\hline Indicator & Value & Number of informants \\
\hline \multirow{3}{*}{ Confidence using the Web } & Very confident & 10 \\
\cline { 2 - 3 } & Moderately confident & 8 \\
\cline { 2 - 3 } & Not very confident & 4 \\
\hline Frequency of Web use & Daily & 13 \\
\cline { 2 - 3 } & Weekly & 9 \\
\hline Hours of Web use per week & $1-5$ & 7 \\
\cline { 2 - 3 } & $5-10$ & 6 \\
\cline { 2 - 3 } & $10-20$ & 5 \\
\cline { 2 - 3 } & $20-40$ & 4 \\
\hline \multirow{3}{*}{ Years using the Web } & $1-3$ & 7 \\
\cline { 2 - 3 } & $4-6$ & 4 \\
\cline { 2 - 3 } & $7-9$ & \\
\hline
\end{tabular}

The informants' levels of experience with the Web ranged from 1 to 9 years, with a mean of 4.6 and a standard deviation of 2.3. Informants who reported using the Web on a daily basis numbered 13; the other 9 used it weekly. When asked to estimate the number of hours they spent using the Web each week, 7 informants reported 1 to 5 hours, 6 reported 5 to 10 hours, 5 reported 10 to 20 hours, and 4 reported 20 to 40 hours. When asked how confident they felt using the Web, 10 informants reported feeling very confident, 8 were moderately confident, and 4 were not very confident.

\section{Experts and Novices Experience Flow}

Web users with both high and low levels of navigation skill recalled past flow experiences during this study. An example of a user with minimal skills who experienced flow was Informant 10, a 28-year-old administrative assistant. She recalled experiencing flow intermittently over a period of three days when she first got a computer with Internet access:

... when I first got my computer at home, and initially loaded all the software on it and first surfed the Net ... I just went from one site to the other. Yeah, and I think I spent about three days on there. [Laughs] ... I had the Complete Idiot's Guide to Surfing the Net in front of me. And that sort of helped me out with search engines and 
stuff like that. But yeah, I think I just went through and clicked and clicked and got pretty well everywhere I wanted to go.

An example of a Web user with extensive skills who experienced flow was Informant 14, a 55year-old reference librarian. At the time of her interview she had used the Web for nine years and spent between ten and fifteen hours online each week. Here is a description of one of her flow experiences:

I was just thinking about the afternoon when I stayed behind after work to look for this particular thing ... I was going from site to site ... There were some very long documents on it, and I was going backwards and forwards between bits of the documents. And I did get quite involved with it ... I really got quite involved in the searching and looking around the thing, and I did lose track of the time. I ended up spending a good half hour more than I originally intended to do, just on this one topic, and in this one site.

\title{
Experts and Novices Experience Frustration
}

Not all searching and browsing activities in the Web environment are enjoyable. Some experiences are very frustrating. During this study both expert and novice Web users recalled frustrating experiences from their past online activities. An example of a Web user with minimal skills who experienced frustration was Informant 2, a 50-year-old a teacher's aide. At the time of her interview she felt very apprehensive about using the Web and estimated that she only used it once every ten days. She recalled becoming frustrated in her attempt to find a 'queer reading' of a film, that is, a textual analysis of a film from a gay perspective:

\begin{abstract}
I'm not scared. I'm not uncomfortable, but I get frustrated 'cause I'm so ignorant that it takes so much of my time and then I don't get a result ... So often when I need to look, I need to have specific words ... If I want to do a mainstream film — which I often do —and I think I want to do a queer criticism of that film, of the relations in it ... I will put in 'queer theory', and then I put the name of the movie ... It will say, 'Can't find anything on this'. And then I'll try and read the instructions which will say, 'You've put in too many words' ... And I might spend half an hour, and then afterwards I find that I've had to put in something like 'reviews' and 'critiques' and put the name of the film ... I find that frustrating 'cause it's time consuming and I don't have that time.
\end{abstract}

An example of a Web user with extensive skills who experienced frustration, was Informant 7, a 22-year-old computer technician. At the time of his interview he felt very confident about using the Web and said that he used it on a daily basis. He recalled becoming frustrated in his attempt to find the meaning of some cryptic runes that appeared on the cover of a book he was reading:

\begin{abstract}
... I'm reading a Lord of the Rings book... They had like a code on the front of the book-the rune code. And I'm trying to work out what that meant. Last night I was trying to work out on a piece of paper what it meant, but I couldn't do it. It was too complicated. And so I went on the Web trying to find the answer to the rune codes. And the problem with that is it turns out that Tolkien for some reason had a hobby of making up his own languages. And he made up like thousands of languages, and some of them are so complex that no one has actually been able to interpret. And so trying to find a simple answer to 'What does that word mean on the front cover?' was pretty hard ... if I know that I've wasted half an hour trying to find an answer or to fail in finding the information I need, then that's sort of half an hour that I felt hasn't been too productive.
\end{abstract}

\section{Balance between Challenges and Skill}

If current theory is correct, and the likelihood of experiencing flow is maximized when the challenges and skills associated with an activity are both high, how does one explain the finding that both novice and expert Web users experience flow? This section discusses the relationship between challenge and skill that is necessary for a flow experience to occur.

One common factor that emerged from the informants' descriptions of their flow experiences was that they were making progress toward attaining their information-seeking goals (see boxes 10 and 15 in Figure 2). Table 9 provides some comments from informants that demonstrate the link between flow experiences and progressing toward a successful outcome.

Table 9. Sample comments from informants that demonstrate the link between flow experiences and progressing toward the attainment of an information-seeking goal. 


\begin{tabular}{|l|l|}
\hline Informant & Comment \\
\hline 2 & $\begin{array}{l}\text { And I thought, 'My God this is a really interesting perspective'. And it suddenly made me } \\
\text { realise that that's what queer theory is about. It says we want to move away from the } \\
\text { bipolar or the binary of homosexual and heterosexual, and take in race, ethnicity ... And } \\
\text { it just suddenly clicked, and so I think I spent, on that particular time I spent five hours } \\
\text { just reading stuff. }\end{array}$ \\
\hline 9 & $\begin{array}{l}\text { I remember when all this stuff started in Afghanistan and that, I hopped on the Web. It } \\
\text { was the Sunday after it all happened and I was just ... like for about three hours ... I } \\
\text { don't know where I went to first. But it was like a new site. And then I went to all these } \\
\text { different links to Afghanistan, and then to the history of the country and all the problems } \\
\text { it had before, and how the Taliban have been dictating for the last however many years. } \\
\text { So I really went to lots of different places. Because I guess it was topical and I guess I } \\
\text { was interested in what was going on. Yeah. So that was long. That was more than two } \\
\text { hours I think. }\end{array}$ \\
\hline $\begin{array}{l}\text { I was searching for something in particular. It was on Zen Do Kai, which is a martial arts } \\
\text { in Australia. And I was just interested to find out a bit more about the culture and back- } \\
\text { ground of it—-how widespread it is. And I stumbled across a really good Web page for it } \\
\ldots \text { Everything on there was about what I needed to find. I kept exploring the links in this } \\
\text { site and it was very interesting - the information I was finding. Before I knew it, easily } \\
\text { half an hour was gone and I thought it was only five minutes. }\end{array}$ \\
\hline
\end{tabular}

When a Web user fails to make progress toward attaining his or her information-seeking goal, the situation does not have the potential to induce flow. Rather, the experience becomes frustrating (see boxes 11 and 14 in Figure 2). Recall that a Web user's goal typically has two components: (1) finding an item of interest; and (2) doing so quickly. Failure to satisfy either of these requirements may lead to frustration. Table 10 provides comments from informants describing the frustration that results when an item of interest cannot be found or when a search takes too much time.

Table 10. Sample comments from informants describing the frustration that results when an item of interest cannot be found or when a search takes too much time.

\begin{tabular}{|l|l|}
\hline Informant & Comment \\
\hline 5 & $\begin{array}{l}\text { If I'm on a timeframe and I'm trying to search for something and I can't get to it, then I } \\
\text { find that frustrating. }\end{array}$ \\
\hline 14 & $\begin{array}{l}\text {.. sometimes it really does take a long time to find what I want when you have to go } \\
\text { back and rethink search strategies and things like that. The time that it takes to some- } \\
\text { times refine what it is, so that you can get what you need, that I sometimes find frustrat- } \\
\text { ing. }\end{array}$ \\
\hline 18 & $\begin{array}{l}\ldots \text { it's a bit frustrating because you think, 'There's so much out there; why couldn't I have } \\
\text { found that now?' }\end{array}$ \\
\hline
\end{tabular}

It is impossible to specify precisely the point at which feelings of frustration arise during a fruitless information-seeking activity because it depends on the user's sense of time urgency. For example, Informant 8 said that in some circumstances he can spend 'a good fifteen or twenty minutes searching for something' before the search 'starts to get annoying'. A different user searching for a different topic under different circumstances might have a very different tolerance level. 
The success or failure of an information-seeking activity depends upon the balance between the challenge of the activity and the Web user's skill or capacity to find whatever he or she is seeking (see box 9 in Figure 2). When the challenge of the activity is matched by the user's skill, the user makes progress toward a successful outcome and the experience has the potential to induce flow. When the challenge of the activity exceeds the user's skill, the user fails to find whatever he or she is seeking within an acceptable time, and the experience becomes frustrating. The determining factor is not the absolute challenge of the activity, nor the absolute level of the user's skill, but rather the relative balance between the two. Table 11 provides some comments from informants who recognized this point.

Table 11. Sample comments from informants referring to the balance between the challenge of an information-seeking activity and the Web user's skill in meeting that challenge.

\begin{tabular}{|l|l|}
\hline Informant & Comment \\
\hline 7 & $\begin{array}{l}\text {.. the thing I find most frustrating is the time it could possibly take to find what I want, } \\
\text { and whether or not that's my fault because I don't know how to search properly or if } \\
\text { that's because the information I'm trying to find is a little bit harder ... it's a little bit, you } \\
\text { know, not too common and people don't really have that much information available for } \\
\text { it ... Hopefully I suspect it's the second one. [Laughs] Looking in all the wrong places. }\end{array}$ \\
\hline 10 & $\begin{array}{l}\text {... I'm sure that if I spoke to other people, they may not experience what I do because } \\
\text { they probably use it a bit more frequently or something like that. Or they have more ex- } \\
\text { perience in searching for specific things. }\end{array}$ \\
\hline 15 & $\begin{array}{l}\text { It's all right for someone like me because I use the Web every day and I have been for } \\
\text { eight years. But for new people-because I run a lot of the classes here at the Li- } \\
\text { brary—-new people are just absolutely overwhelmed by something like that. }\end{array}$ \\
\hline
\end{tabular}

In order to achieve flow, a Web user must perceive the challenge of an information-seeking activity to be high in relation to his or her skills, but not so high that it is unreachable. Since all Web users have different interests and different skill levels, the searching and browsing activities that they find suitably challenging will differ also. To illustrate this point, consider the challenge associated with typing a URL into a Web browser's address bar. For an experienced Web user, entering a URL might not present much of a challenge at all, but for a novice Web user the challenge could be significant. Informant 21 , a Web user with minimal experience, mentioned this point:

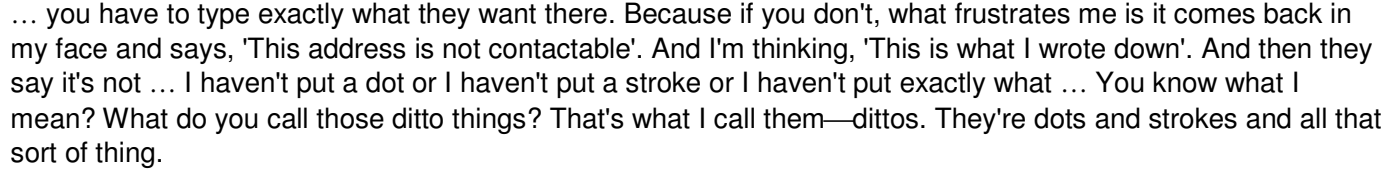

Evidently an activity that one user finds challenging enough to hold his or her attention may be too challenging for another user, and not challenging enough for yet another user. Part of the reason why both expert and novice Web users can experience flow while searching for information is the Web's capacity to immediately provide a challenge that matches any individual's interests and level of skill. In some non-Web-related flow activities, the balance between challenge and skill is lost as the participant's ability increases, but that does not happen in the Web environment. For example, a squash player whose game improves faster than her regular opponent may need to seek a more challenging partner to restore balance to the game. This kind of time-consuming obstacle to flow is not an issue for Web users who can quickly adjust their goal or mode of navigation to suit their level of ability. Kubey and Csikszentmihalyi (2002, p. 68) have made a similar comment about experiencing flow while playing computer games: 
Many video and computer games minutely increase in difficulty along with the increasing ability of the player. One can search for months to find another tennis or chess player of comparable ability, but programmed games can immediately provide a near-perfect match of challenge to skill. They offer the psychic pleasure — what one of us (Csikszentmihalyi) has called "flow"- that accompanies increased mastery of most any human endeavour.

\section{Focused Attention}

Making progress toward a successful outcome may be a necessary condition for flow in searching and browsing activities, but it is not a sufficient condition. Another essential factor is focused attention on the task at hand (see box 13 in Figure 2). Informant 1 described flow this way: 'It's a total concentration experience. You're so interested in doing what it is you're doing that nothing's interrupting you'.

The higher-than-average challenges associated with searching and browsing activities in the Web environment play a significant role in focusing attention on the task at hand. Interesting content and links also help to attract and maintain a Web user's attention (see box 8 in Figure 2). Comments from the informants suggested several reasons why users find certain content interesting. Relevance to one's current information-seeking goal, congruence with personal interests and novelty were all key factors. Content properties such as credibility, correctness, currency, ease of understanding, rarity, emotional impact and aesthetic appeal also seem to be influential in maintaining a user's attention under some circumstances.

Control over attention can be either voluntary or involuntary. Although people are able to voluntarily focus their attention on particular stimuli, attention may be involuntarily diverted by stimuli outside one's attentive focus (see box 12 in Figure 2). The study's informants mentioned three different kinds of distractions that interfered with their flow experiences: environmental distractions such as loud noise or interruptions from family members; physiological distractions such as hunger, fatigue or a need to use the toilet; and computer-related distractions such as software error messages, a broken Internet connection, or a browser that stops responding (see box 7 in Figure 2). Web users generally ignore minor distractions during a flow experience because their attention is focused on the task at hand. But an event that is distracting enough to shift the user's attention will terminate a flow experience.

A Web site's user interface can also be a distraction (see box 4 in Figure 2). Ideally, interaction with a Web interface should require minimal attention, thereby freeing the user to concentrate on the task at hand. A poorly designed interface that demands an excessive amount of attention can disrupt a flow experience. The study's informants mentioned several examples of interface design elements that interfered with their flow experiences: lengthy response times, disorganized content, inconsistent navigation cues, poorly structured page layout, inappropriate use of color, stale links, ambiguous link labels, and pop-up advertisements.

\section{Dimensions of Flow}

The flow experiences described by the study's informants varied in duration, frequency and intensity. Informants recalled flow experiences ranging in duration from a few minutes to several hours. Some informants claimed to experience flow on an almost daily basis, while for others it was a much less frequent occurrence. Dimensions of the flow experience that were evident from the informants' comments are briefly described below.

Joy of discovery. According to Csikszentmihalyi (1990, pp. 67-69) enjoyment is a common characteristic of all flow experiences, but among Web users it appears to be linked to discovery—finding, learning or observing something for the first time (see box 16 in Figure 2).

Reduced awareness of irrelevant factors. One of the consequences of a Web user's attention being focused on an information-seeking activity during flow is that there is no room leftover in one's 
consciousness for irrelevant thoughts (see box 17 in Figure 2). Informants reported having a reduced awareness of their physical surroundings, their interactions with other people, their usual worries and concerns, their physical needs, the navigation path they followed, and even their original reason for using the Web.

Distorted sense of time. Informants reported that time seemed to pass much faster than usual during their flow experiences (see box 18 in Figure 2). Hours slipped by as if they were minutes. Focused attention appears to be the key factor affecting the variability of a Web user's time judgments (Brown \& Boltz, 2002, p. 600). Presumably the thought of time passing doesn't enter a user's consciousness during flow because it is irrelevant to the task at hand, just like the factors that were mentioned in the previous paragraph.

Merging of action and awareness. A few informants recalled becoming so involved in their flow experiences in the Web environment that their activities seemed to be spontaneous or automatic. The usual dualism between the individual and his or her actions disappeared (see box 19 in Figure 2).

Sense of control. The flow experiences of some informants involved a sense of control (see box 20 in Figure 2). In some cases this feeling manifested itself as an absence of any concerns about failure, even when searching for very specific and uncommon information. In other cases informants experienced a sense of empowerment that displaced their usual feelings of inadequacy around computers.

Mental alertness. Some informants recalled feeling more mentally alert during their flow experiences, even though they were physically tired when they started using the Web (see box 21 in Figure 2).

Telepresence. A few informants felt as though they were present in the environment generated by the computer during their flow experiences. This sense of telepresence was particularly evident in the comments of an informant who experienced flow while exploring three-dimensional virtual environments on the Active Worlds site (http://www.activeworlds.com). Focused attention appears to be a key determinant of feelings of telepresence (Witmer \& Singer, 1998, p. 226).

Pace (2004) provides further details about these dimensions of flow, as experienced by Web users.

\section{Conclusion}

This paper has identified specific challenges that Web users face when engaged in informationseeking activities: negotiating a vast, constantly changing, uncharted information space; selecting suitable key words for a search engine query; using the correct syntax for a search engine query; distinguishing relevant links from irrelevant links; dealing with a large collection of potentially relevant links; scanning a page for relevant information; and understanding the content and nonlinear structure of a Web site. Future investigations into the flow experiences of Web users could use this information to properly operationalize the construct of challenge, rather than treat it as a general experience of Web users as Novak et al. (2000) have done.

This paper has also explored the roles that challenge and skill play in the flow experiences of Web users. It proposed that a necessary condition for experiencing flow while searching or browsing for information on the Web is that the challenge of the activity must be matched by the Web user's skill or capacity to find whatever he or she is seeking. Other elements of the overall grounded theory that were briefly discussed include information-seeking goals, the need for focused attention on the task at hand, and specific dimensions of the flow experience. 
Developing a better understanding of the flow experiences of Web users is important because there is evidence to suggest that the behavior of users toward new information technologies is shaped by their holistic experiences with the technology, and not just the usability or instrumentality of the technology. Agarwal and Karahanna (2000, p. 688) suggest that 'as technology developments continue to focus on richer and more appealing interfaces, the importance of experiences that are intrinsically motivating, i.e., pleasurable and enjoyable in and of themselves, might dominate as predictors of usage intentions'. A better understanding of the elements that contribute to flow experiences could help designers to create online environments that are genuinely engaging rather than merely usable.

\section{References}

Agarwal, R. \& Karahanna, E. (2000). Time flies when you're having fun: Cognitive absorption and beliefs about information technology usage. MIS Quarterly, 24 (4), 665-694.

Brown, S. W. \& Boltz, M. G. (2002). Attentional processes in time perception: Effects of mental workload and event structure. Journal of Experimental Psychology: Human Perception and Performance, 28 (3), 600-615.

Chen, H., Wigand, R. T. \& Nilan, M. (1998). Optimal flow experience in Web navigation. In M. Khosrowpour (Ed.), Effective utilization and management of emerging information technologies (pp. 633-636). Hershey, Pennsylvania: Idea Group Publishing.

Chen, H., Wigand, R. T. \& Nilan, M. S. (1999). Optimal experience of Web activities. Computers in Human Behavior, 15 (5), 585-608.

Chen, H., Wigand, R. T. \& Nilan, M. (2000). Exploring Web users' optimal flow experiences. Information Technology \& People, 13 (4), 263-281.

Csikszentmihalyi, M. (1975). Beyond boredom and anxiety: The experience of play in work and games. San Francisco, California: Jossey-Bass Publishers.

Csikszentmihalyi, M. (1990). Flow: The psychology of optimal experience. New York: HarperPerennial.

Csikszentmihalyi, M. (1999). If we are so rich, why aren't we happy? American Psychologist, 54 (10), 821827.

Glaser, B. G. (1978). Theoretical sensitivity: Advances in the methodology of grounded theory. Mill Valley, California: Sociology Press.

Glaser, B. G. (1992). Basics of grounded theory analysis: Emergence vs. forcing. Mill Valley, California: Sociology Press.

Glaser, B. G. (1998). Doing grounded theory: Issues and discussions. Mill Valley, California: Sociology Press.

Glaser, B. G. \& Strauss, A. L. (1967). The discovery of grounded theory: Strategies for qualitative research. New York: Aldine De Gruyter.

Hoffman, D. L. \& Novak, T. P. (1996). Marketing in hypermedia computer-mediated environments: Conceptual foundations. Journal of Marketing, 60 (3), 50-68.

Jackson, S. A, \& Csikszentmihalyi, M. (1999). Flow in sports. Champaign, Illinois: Human Kinetics.

Koufaris, M. (2002). Applying the technology acceptance model and flow theory to online consumer behavior. Information Systems Research, 13 (2), 205-223.

Kubey, R. \& Csikszentmihalyi, M. (2002). Television addiction is no mere metaphor. Scientific American, 286 (2), 62-68.

Nel, D., van Niekerk, R., Berthon, J. \& Davies, T. (1999). Going with the flow: Web sites and customer involvement. Internet Research: Electronic Networking Applications and Policy, 9 (2), 109-116. 
Roles of Challenge and Skill

Nielsen, J. (2000). Designing web usability: The practice of simplicity. Indianapolis, Indiana: New Riders Publishing.

Novak, T. P., Hoffman, D. L. \& Yung, Y.-F. (2000). Measuring the customer experience in online environments: A structural modeling approach. Marketing Science, 19 (1), 22-42.

Pace, S. (2004). A grounded theory of the flow experiences of Web users. International Journal of HumanComputer Studies, 60 (3), 327-363.

Witmer, B. G. \& Singer, M. J. (1998). Measuring presence in virtual environments: A presence questionnaire. Presence, 7 (3), 225-240.

\section{Biography}

Dr Steven Pace is a senior lecturer and coordinator of the Bachelor of Multimedia Studies program at Central Queensland University. His research interests include multimedia design and development, human-computer interaction, grounded theory and flow. Steven has recently completed a PhD with the Australian National University on the subject 'Understanding the flow experiences of Web users'. 